\title{
A Two-Stage Assessment of the Remote Engineering Lab VISIR at Al-Quds University in Palestine
}

\author{
Salaheddin Odeh, Joaquim Alves, Gustavo Riberiro Alves, Member, IEEE, Ingvar Gustavsson, Member, IEEE, \\ Mahasen Anabtawi, Labib Arafeh, Mahran Jazi, and Mahmoud R. Arekat
}

\begin{abstract}
Engineering labs are an essential part in engineering education, since they provide practical knowledge for students, illustrate concepts and principles, and improve technical skills. Remote labs allow devices, equipment, and instrumentations to be shared with other universities. In addition, they relax time and space constraints, and are capable of being adapted to the pace of each student; in the case, there was insufficient time in the laboratory. This paper describes an empirical study, which embeds two stages of assessment. In the first stage, we are concerned with finding out the level of flexibility when applying the engineering remote lab VISIR as a contemporary remote lab technology in the engineering faculty at Al-Quds University in Jerusalem in Palestine, and whether the engineering students will accept such technology to interact with in their future lab courses or not. In the second stage of the assessment study, a more in-depth comparative analysis will be carried out in order to have a categorization of VISIR in the landscape of the engineering labs, such as hands-on and simulations. The three lab approaches will be compared with each other by means of an experimental testing based on assessment criteria that are in accordance with the fundamental course objectives of engineering instructional labs: student's retention rate and satisfaction survey, as well as their performance.
\end{abstract}

Index Terms-VISIR, remote labs, survey instruments, comparative evaluation, design criteria.

\section{INTRODUCTION}

$\mathbf{E}$ NGINEERING is mainly distinguished from other branches of science by its applied perspective. Engineers transform bare knowledge into tangible useful technologies devoted to the welfare of human kind. Engineering harnesses the natural, fundamental and available resources for the creation of thousands of new products, services and machines. On the one hand, courses are responsible for preparing the students with the adequate information they need to design, improve, evaluate, develop, and create; on the

Manuscript received February 20, 2015; revised May 19, 2015; accepted June 15, 2015. Date of publication July 13, 2015; date of current version October 19, 2015

S. Odeh, M. Anabtawi, L. Arafeh, M. Jazi, and M. R. Arekat are with the Department of Computer Engineering, Faculty of Engineering, Al-Quds University, Jerusalem 20002, Palestine (e-mail: sodeh@eng.alquds.edu; manabtawi@eng.alquds.edu; larafeh@eng.alquds.edu; eng.mahranjazi@ gmail.com; arekat.mahmoud@gmail.com).

J. Alves and G. R. Alves are with the Polytechnic of Porto, School of Engineering, Porto 4249-015, Portugal (e-mail: jaa@isep.ipp.pt; gca@isep.ipp.pt).

I. Gustavsson is with the Blekinge Institute of Technology, Karlskrona SE-371 79, Sweden (e-mail: ingvar.gustavsson@bth.se).

Color versions of one or more of the figures in this paper are available online at http://ieeexplore.ieee.org.

Digital Object Identifier 10.1109/RITA.2015.2452752 other hand, labs give them the chance to practice, implement and learn things that engineers are assumed to already know. Labs supply students with better understanding of theories, and many of them are connected to future employment.

Through the educational goals proposed by ABET, it is evident that labs play a central role in illustrating concepts and principles, providing the ability to design and investigate, promoting social skills and improving technical skills. ABET is a nonprofit, non-governmental organization that accredits college and university programs in the disciplines of applied science, computing, engineering, and engineering technology [1]. Engineering students must have better understanding of the instructed theory; therefore most courses in engineering education require labs [2], [3].

Laboratory experiments make science come alive; they represent the heart of engineering learning as they supply students with better understanding of scientific theories. There are three categories of laboratories: hands-on, simulators, and remote labs. Hands-on labs are costly and put high demands on space, instructor time, and infrastructure. Simulators are imitators of real life experiments with low precision due to mathematical approximation techniques applied by simulation software, which might be a major obstacle for experiments that need high accuracy.

Remote labs enable both sharing the devices with many universities and they also relax time constraints, adapting to the pace of each student in case there was insufficient time in the laboratory. There are further advantages obtained through introducing remote labs as a complementary asset to traditional hands-on [4]. These include, for example, relaxing geographical constraints, disregarding the physical locality of the student, allowing the sharing of large fixed costs of traditional buildings, improving quality of experiment, as it can be repeated to clarify doubtful measurements in lab, improve effectiveness by rehearsal, improve safety and security, as there is no risk of catastrophic failure. However, they lack hands-on troubleshooting and debugging experience, and lack equipment setup experience. The boundaries among the three categories are blurred in the sense that most labs are mediated by computers, and that the psychology of presence may be as important as technology [5].

In this paper, the remote lab system VISIR (Virtual Instrument Systems in Reality) [6] was applied in the Engineering Faculty at Al-Quds University in Jerusalem in Palestine. 
VISIR is a remote lab for designing, wiring and measuring electronic circuits. The user has the ability to access the lab remotely at any location by using the Internet and a Web-based user-interface using any Web browser. The project was launched at the end of 2006 by the Signal Processing Department ASB at the Blekinge Institute of Technology (BTH) in Sweden together with National Instruments in USA, as a supplier of instruments, and Axiom EduTECH in Sweden. The project was financially supported by BTH and the Swedish Governmental Agency for Innovation Systems (VINNOVA).

It is well known that remote labs must be supportive and not substitutive to on-campus labs. In other words, they must serve as a complementary asset to traditional hands-on laboratories, enabling students to access remote labs outside the ordinary lab hours in order to enhance their learning concepts and theory [5]. This contribution reports the experiences at Al-Quds University in Jerusalem in Palestine with applying VISIR, and represents the results of an evaluation of its design. It shows whether VISIR fulfills this goal from the perspective of the students enrolled in the Engineering Faculty at Al-Quds University. It also exposes the advantages and disadvantages achieved by using this remote lab. The assessment procedure is organized as a two-stage assessment approach.

In the first stage the emphasis was placed on finding out whether VISIR is appropriate as a complementary asset to hands-on labs. In this stage, the questionnaire for the interaction between students and VISIR includes survey questions with the goal of measuring the evaluation criteria: usefulness and satisfaction, sense of reality/immersion and usability. Therefore, it was necessary to choose a suitable experiment to simplify the interaction between students and VISIR. The RC filter experiment was chosen for many reasons. First of all, an RC filter experiment is simple and does not need many components to apply. Moreover, the main goal of the experiment is to try the VISIR lab and not to try hard circuits. Another reason is that students practiced the RC filter circuit experiment before in the traditional labs, and they discussed it and understood it deeply by means of their reports and projects. Thus, when they apply it on the new system, they can mention the difference and it is easy for them to compare, leading to the fact that they can judge the system themselves, and this is the main goal of our study. During the usability testing, the students were asked to answer a survey; one part must be answered after the hands-on and before the remote lab experiment, while the other is answered after performing the VISIR experiment.

In the second stage, which will be at the beginning of the next academic year 2014/2015, a comparative assessment with a group of more than 50 electronics and computer engineering students will be carried out. A more complicated electronic circuit, namely a common emitter amplifier circuit for measuring either the lower or upper cutoff frequencies is selected, since the goal of this evaluation is to find out strengths and weaknesses of remote labs represented here by VISIR compared with their traditional and simulation equivalences. As the traditional and simulated labs serve as references, it is possible to compare and analyze the statistical results to be accomplished using one of the statistical testing techniques available such as ANOVA and t-test [7]. Since the number of subjects is more than 30 and we have two reference systems, the choice will be for ANOVA as it is more suitable for such kind of complicated evaluations. Afterwards, the raw data of the comparative usability testing will be handled and analyzed statistically using SPSS [8]. Through this comparative evaluation, it is possible to find out in which criteria VISIR is superior or inferior to the other two approaches. The three approaches will be compared with each other by means of an experimental testing, in which some selected assessment criteria such as student's retention rate and satisfaction survey, as well as their performance are used.

\section{HANDS-ON, ViRTUAL AND REMOte LABS}

Engineering is considered an applied science. Most engineering curricula contain a minimum level of credit hours assigned to lab experiments. Students need to perform experiments in order to gain better understanding of theories, to collaborate and interact efficiently with their colleagues and to learn how to deal efficiently with equipment and instruments, which will be of a vital role after their graduation. Two characteristics differentiate hands-on labs from the other types [9]. On the one hand, the real equipment used in the lab is physically and locally connected, and on the other, the students and the equipment must be present in the same place of the lab; however, due to space and money limitations, many engineering courses cannot be offered with their practical part using the traditional labs. Consequently, usage of virtual labs (simulation lab) and remote labs has increased rapidly in engineering education.

A virtual lab is a software simulation, which is an imitation of a real experiment represented by a mathematical model. In other words, virtual labs imitate hands-on ones; that is, instead of performing the experiment on actual equipment, the tests and possibly even the data are simulated on a computer [3]. Unfortunately, this weakens students' reference to reality, and thus, they cannot later deal with these components and instruments in real work. Furthermore, most of such mathematical models lack accuracy, which might be crucial for many experiments. Recently, e-learning technologies have greatly changed the environment of labs. By using text, pictures, illustrations, and multimedia, we can build simulations of complex processes of biological and medical sciences, agriculture, engineering and educational practice, which are not easily accessible in real time and settings. When a simulation replaces a real system, virtual labs typically resort to simulation software such as MATLAB, LabVIEW or other applications. Virtual labs enable the students to access the engineering applications easily anytime and anywhere. Examples of these engineering applications are simulations, demonstrations, and exercises.

Remote labs highly benefit from contemporary e-learning and Internet technologies. Recently, many academic institutions provide a variety of remote lab experiments designated as Web-based labs or online labs; these labs support remotely controlled physical experiments [10]. A remote lab may be defined as a lab accessed via a communication network in order to execute a lab experiment; thus, it uses real devices 


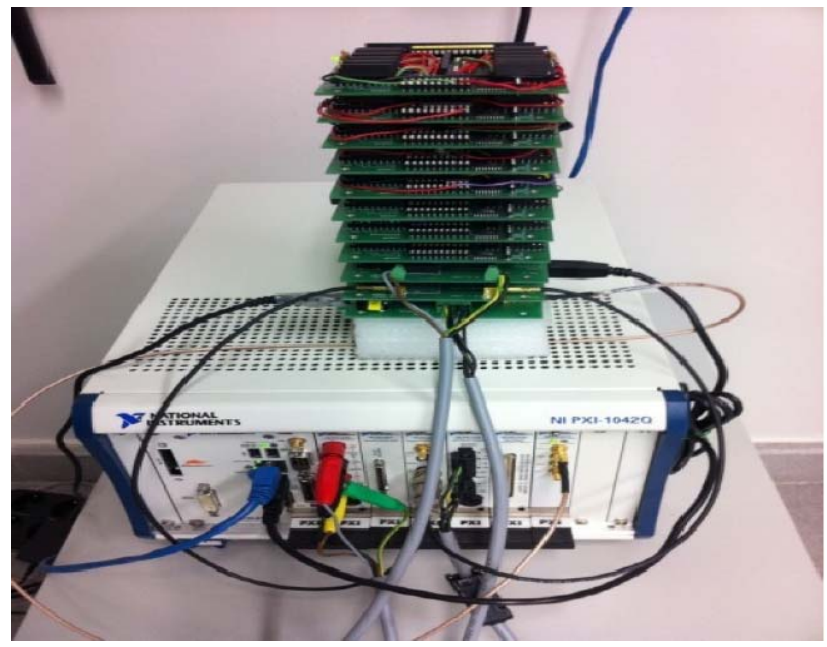

Fig. 1. VISIR hardware platform at University of Deusto.

and equipment. The lab server communicates between the user and the physical experiment in the lab [11]. This type of lab is suitable for distance learning courses where students do not need to be locally present on campus. The core of a remote lab is the instruments that are controlled through a personal computer. These instruments can be remotely configured by software that makes it easy to share the expensive instruments and equipment. A remote lab must be provided with an interface to send commands and receive feedback from the lab equipment. Many methods provide remote access to the lab equipment; the most general method is to use a Web browser such as Internet Explorer and Firefox. Usually, user access is then regulated by a specific time schedule.

\section{VISIR REMOTE LAB}

The VISIR Open Lab Platform designed at the Department of Electrical Engineering (AET), the Blekinge Institute of Technology (BTH), Sweden, is an architecture for opening existing types of hands-on labs for remote access with preserved context in order to, in the first place, supplement and increase the accessibility and the capacity of them. A unique interface gives the student a feeling of being in the handson lab [12]. Some types of labs are easier to open for remote access than others are. So far, the current VISIR platform (4.1) supports labs for electrical experiments and for mechanical vibration experiments.

Most instruments in an electronics lab have a remote control option but the breadboard does not. To open a workbench for remote access, a remotely controlled wiring manipulator is required. A switching matrix equipped with electro-mechanical relays can serve as such a device [13]. The switching matrix for remote wiring of electrical circuits is shown in the upper side of the photograph (Fig. 1). It is the card stack on the top of the PXI chassis that contains the instruments.

The VISIR platform has been described in many works [14]-[16]; but here we only want to remark the most important parts of it:
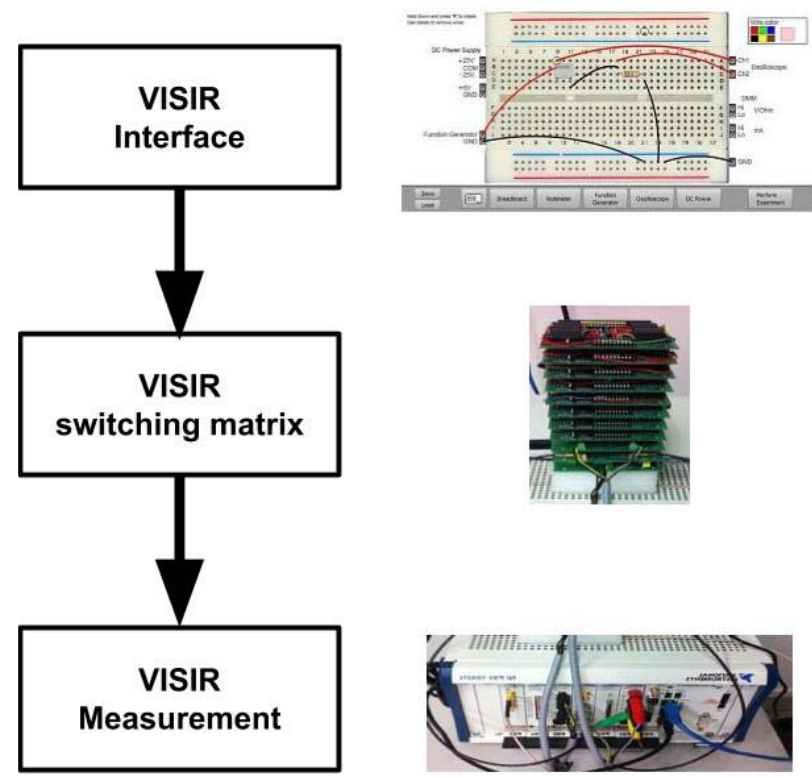

Fig. 2. Practical session work flow using VISIR lab.

- Web Interface: It enables the user to perform the same actions as if she/he was in a hands-on lab. Its powerful interface developed in Adobe Flash represents realistic front panels of the equipment used by the students to test the circuits developed in the virtual breadboard.

- Measurement Server: It acts as a virtual instructor that controls the commands passing from the web interface to the equipment server to prevent hazard circuit designs and protect the instruments. It is programmed by 'max list' files, which contain the maximum component values and instruments adjustments for each experiment and describes the circuits allowed in the platform.

- Equipment Server: The PXI platform is connected to the relay switching matrix, and both are controlled by this server written in LabVIEW. It receives the commands from the measurement server over TCP/IP to be executed on the real instruments. A 'component list' file is inserted to the equipment server to define the components installed on the matrix.

- The Switching Matrix: It is the matrix especially developed for this remote lab that performs the connections between the components and instruments that the user has carried out in the web interface.

Fig. 2 represents graphically the work flow at a VISIR practical session: the web interface allows the student to create the circuit in a virtual way through a web browser while the measurement and equipment server are both in charge of making this circuit real on the switching matrix and provide the user with the measurements obtained from the previously created circuit.

\section{EXPERIENCES With APPLYING VISIR}

\section{A. Applying VISIR at Al-Quds University}

VISIR has been used in the Faculty of Engineering of the University of Deusto since 2007 in different Engineering 
specialization areas: Telecommunication, Computer Science, Industrial Technologies and Electronics. The subjects related with VISIR at this moment are: Digital Electronics, Computer Technology, Analog Electronics, Circuits and Physics [17]. A major goal achieved by applying VISIR at Al-Quds University is not only using it in future experiments as a complementary asset to traditional hands-on labs, but also some kind of academic collaboration between international universities will be established, for example, through sharing devices, equipment and instrumentations.

After having contacted the VISIR group at ISEP in Porto in Portugal and obtaining their acceptance for accessing and testing VISIR using their VISIR lab, it was necessary to decide the circuits that would be used by the students during that semester. As previously argued, we decided for an RC filter experiment because the main goal of the experiment is to try the VISIR lab and not hard circuits. For preparing the virtual session for the remote experimentation, the following deployment steps were necessary:

1. The instructor had to explain to the students how to use VISIR. Thus, it was necessary to allow the instructor to access one of the experiments that were previously prepared and configured. In addition, assistance via one of the contemporary voice-over-IP services such as Skype was possible.

2. An important aspect about the use of VISIR, from a teacher's perspective, is to understand the sort of experiments one can do. For this, it is important to know which components are available in the matrix as shown in Fig. 2. For this purpose, VISIR's developer prepared a simple function that allows the downloading of the components list and the file indicating which maximal number of components is allowed.

3. Instructors had to make themselves familiar with the system by reading the teachers' manual and the VISIR matrix manual.

4. VISIR's administrator prepared a virtual course, which was in our case entitled "Collaboration_ALQuds." An instructor had to be added to this course. Once she/he activated her/his account, she/he got the permission to add students to this course. The number of the students had to be set by the VISIR administrator.

5. After completing the previous steps and logging into the system, we were able to see an experiment window entitled "RC filter" consisting of a virtual breadboard and 5 components on the top bar (4 resistors and 1 capacitor). With these electronic elements, equipment and instrumentations, it was possible to do simple experiments with low-pass and high-pass filters using the preconfigured elements.

In brief, although VISIR is far from Al-Quds University, it was easy through email exchange to coordinate for carrying out the required tasks to prepare the remotely located circuit experiment with simple steps.

\section{B. Evaluating VISIR}

1) Introduction: As shown in the previous section, one major objective of this study is to show the degree of flexibility when applying VISIR in the engineering faculty at Al-Quds University. Moreover, it is also aimed at revealing through a usability testing, mainly based on user questionnaires, whether the engineering students at Al-Quds University will accept such technology to interact with in their future lab courses or not, and what are the advantages and disadvantages of using VISIR from the perspective of the students. To this end, it will be possible to decide to use VISIR in future experiments at Al-Quds University. An obvious way to achieve such a goal is to experiment VISIR via a subjective evaluation [18]. One possible approach to achieve this goal is using survey instruments [18] that represent a familiar, inexpensive and generally acceptable evaluation method. Evaluation of new practical educational systems depends on student surveys to measure the achievement of the required practical skills of the students who have already tried the experience with traditional labs. In a further step, it is of great significance to categorize VISIR in the laboratory landscape by comparing it with other kinds of lab approaches such as hands-on and simulations. One way this can be accomplished is applying a comparative evaluation based on a statistical analysis, aimed at revealing and comparing the characteristics and abilities of VISIR and the other approaches.

In the literature, there are many sources that can be used to establish the questionnaire of this study, for example, questionnaire of user interaction satisfaction (QUIS) [19], software usability measurement inventory (SUMI) [20], measuring usability of multimedia systems (MUMMS) [21], computer system usability questionnaire (CSUQ) [22], and questionnaires that deal with human-computer interaction [23].

2) Stage One (A Usability Testing Based on Survey Instruments): Irrespective of the evaluation techniques mentioned above, the survey questions of this study were mostly established using the survey of Tawfik et al. [17] since it was previously used to evaluate the same remote lab and, thus, it was proven for its appropriateness for this testing.

A survey questionnaire of closed-ended questions was implemented and the raw data was collected in order to investigate student perceptions of their experiences with hands-on and VISIR as a representative of remote labs for this case study. Closed-ended questions are questions in which all-possible answers are ordered in a five degrees scale (Likert scale); the respondent is asked to choose one of the answers (Strong disagreement, Disagreement, Neutral, Agreement, Strong Agreement). According to Reja et al. [24], closed-ended questions have several advantages: they are generally more straightforward and offer choices for respondents, they guide respondents to specific information needed, they permit to ask more questions in less time, and the data (answers) are easy to tabulate and analyze.

This kind of evaluation can be considered as scenario-based usability engineering consisting of user-interaction scenarios. According to Rosson and Carroll [25], a user-interaction scenario is a story about people and their activities and helps designers respond to current needs while also anticipating new needs. They offer insight into meaning situations, but at the same time do not imply that things will stay the same. They describe systems in terms of the goals that people 


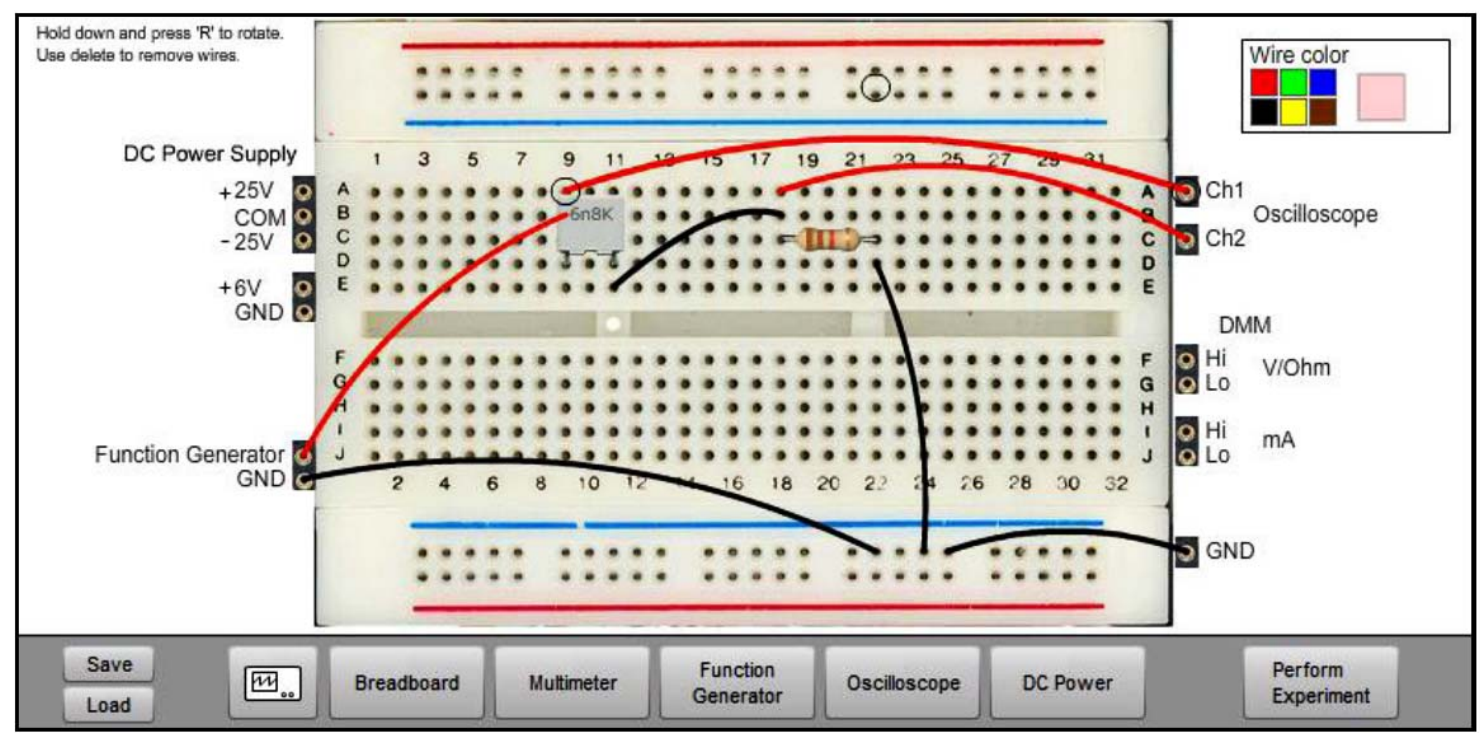

Fig. 3. The virtually connected RC filter circuit on the virtual breadboard of the VISIR remote lab.

will be pursuing as they use the system. In short, scenarios focus designers on the needs and concerns of people in the real world. Scenario-based methods both for designing and analyzing are not only beneficial for describing people using technology in order to reshape their activities, but might be of great significance before a system is built and its impacts felt, [26], [27].

A total of 71 engineering students (34 females and 37 males) from the Computer Engineering Department at Al-Quds University were involved in answering the survey questions of the first evaluation stage. These students were enrolled in the course "Instrumentations and Control Systems" and had a strong background in analog circuit principles as well as a keen intuition about their applications and implementations. The lab experiment used is an RC filter circuit and for carrying it out, electrical components in addition to instruments such as oscilloscopes, function generators etc. are needed.

During the RC filter experiment, which represents the formerly discussed usability testing session, the usability engineer explains to the subjects (the students) all operations related to using VISIR in a very simple and clear manner. As it is obvious, the RC circuit is a simple one and it was chosen in order to simplify the interaction between students and VISIR. There are also of other reasons, for example, an RC filter experiment is simple and does not need many components to apply. The goal of the study is to try VISIR and not to try hard circuits. All of the subjects, the students, had the experience with RC filter circuits. Accordingly, they were able to distinguish and compare between the two different interaction approaches and then judge the system. One major graphic component on the client Web-based user-interface of the VISIR remote lab is the virtual breadboard, through which the students can connect the remote physical components and equipment with each other for obtaining the desired experimentation circuit. Fig. 3 shows the virtually connected RC filter circuit on the virtual breadboard of VISIR. While Table I includes the measured and calculated gain values and
TABLE I

Measured And Calculated Values of the RC Filter ACHIEVED by ONE of THE SubJects

\begin{tabular}{|c|c|c|c|}
\hline Frequency $(\mathbf{H z})$ & Gain Measured & Gain Calculated & Gain Error \\
\hline 300 & 0.68 & 0.73 & 6.85 \\
\hline 400 & 0.60 & 0.63 & 4.76 \\
\hline 500 & 0.51 & 0.54 & 5.56 \\
\hline 600 & 0.45 & 0.47 & 4.26 \\
\hline 700 & 0.40 & 0.42 & 4.76 \\
\hline 800 & 0.35 & 0.37 & 5.41 \\
\hline 900 & 0.33 & 0.34 & 2.94 \\
\hline 1000 & 0.30 & 0.31 & 3.23 \\
\hline 1600 & 0.19 & 0.20 & 5.00 \\
\hline 2600 & 0.12 & 0.12 & 0.00 \\
\hline 3600 & 0.08 & 0.09 & 11.11 \\
\hline
\end{tabular}

the resulted errors achieved by one of the subjects, in Fig. 4, snapshots of the displayed VISIR oscilloscopes are presented. They show input and output sine signal graphs of the RC filter circuit with different frequencies. It is to note that the gain error is due to the tolerances of the equipment in Porto.

It is undeniable that remote labs must be supportive and not substitutive to on-campus labs. In other words, they must serve as a complementary asset to traditional hands-on labs, enabling students to access remote labs outside the ordinary lab hours in order to enhance their learning concept and theory [5]. Therefore, the used survey questionnaire consists of a group of questions (Q1-Q3) for gaining an imagination about the students' opinion about difficulties they face in traditional labs. Such difficulties are caused by attending practical sessions in campus-based labs at a fixed time during the academic year, which restricts access to lab resources at normal working hours, leading to the fact that an increased number of students must work on the same experiment as a result of shortages of lab equipment and instruments due to budgetary limitations [5].

Table II includes the survey questions categorized with "before" to evaluate the satisfaction of the students regarding 


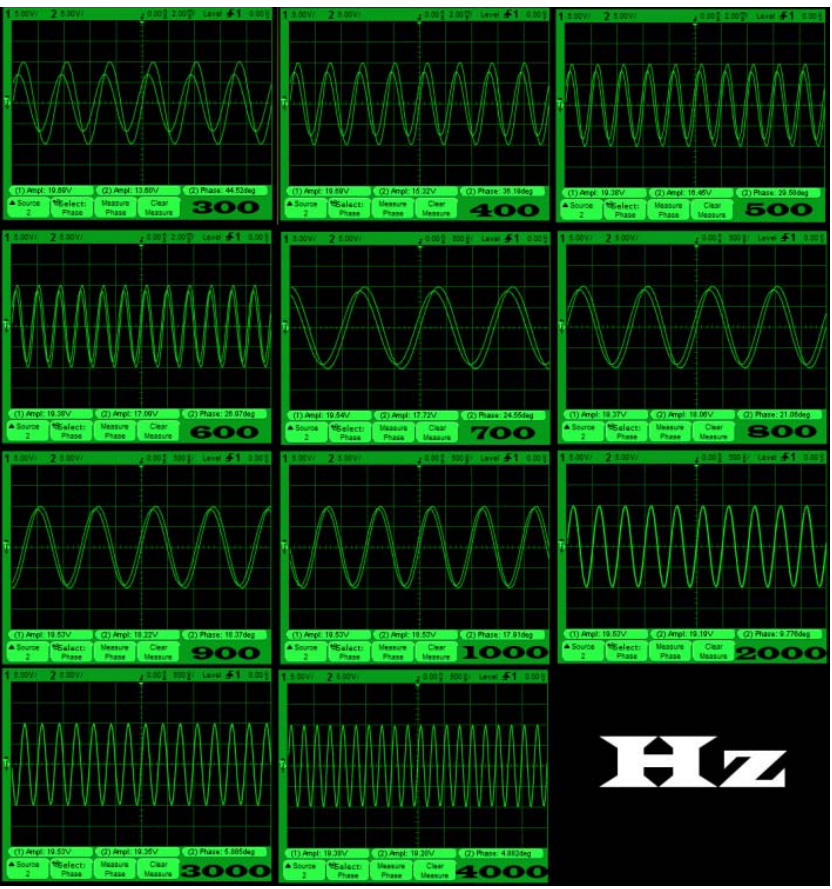

Fig. 4. Snapshots of the displayed VISIR oscilloscope achieved by one of the students having carried out the RC filter circuit experiment.

how much they are satisfied with the traditional lab equipment and management (Q1-Q3). Another criterion to evaluate the interaction with VISIR is to measure the sense of reality/ immersion, which serves as examination of the reality/ immersion strength of real world and virtual world in the manufactured environment [28]. Its measurement value exposes that the students are immersed in their activity of carrying out experiments through the VISIR remote lab. Moreover, the questionnaire includes survey questions (Q4-Q17) to measure these evaluation criteria: "usefulness and satisfaction", "sense of reality/immersion" and "usability". These questions that will be answered after the session are classified as "after". With these questions, it is possible to reveal how much VISIR is user-friendly and easy to use. Moreover, we can measure the students' satisfaction about VISIR's ability to function correctly and to give the expected results because of the fact that the students were already experienced with the RC circuit experiment through the traditional lab, as well as how much they find VISIR useful to complement hands-on sessions and the collaborative working between them.

At the beginning of the experiment, the usability engineers gave the students the username and password for allowing them to access VISIR through the Web-based user-interface. As mentioned, the subjects (the students) had to answer two surveys, one before and another after the experiment. After the experiment sessions, the raw data were collected and statistically analyzed. In the following, some of the results of the survey questionnaire, which are represented in Fig. 5, are discussed. From Fig. 5, it is obvious that the students' satisfaction about attending practical sessions in the traditional labs at a fixed time during the academic semesters is low since this restricts access to lab resources at normal working hours
TABLE II

SURVEY QUESTIONS OF THE EVALUATION

\begin{tabular}{|c|c|c|}
\hline $\begin{array}{c}\text { Survey } \\
\text { time }\end{array}$ & $\begin{array}{c}\text { Evaluation } \\
\text { Criterion }\end{array}$ & Survey question \\
\hline \multirow{3}{*}{ 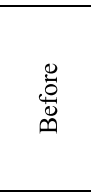 } & \multirow{3}{*}{ 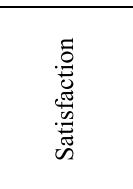 } & $\begin{array}{l}\text { Q1 I feel that results achieved in traditional labs } \\
\text { are in accordance with the intended learning } \\
\text { outputs of the lab experiments }\end{array}$ \\
\hline & & I face a lot of troubles in the traditional lab \\
\hline & & $\begin{array}{l}\text { Q3 After carrying out an experiment in the lab, I } \\
\text { wish I had more time to exercise more on it }\end{array}$ \\
\hline \multirow{14}{*}{$\sum^{\grave{2}}$} & \multirow{6}{*}{ 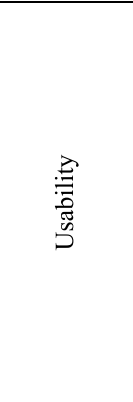 } & Q4 Using VISIR is easy and convenient \\
\hline & & $\begin{array}{l}\text { Q5 I don't need the assistance of the experiment } \\
\text { tutor in most of the activities }\end{array}$ \\
\hline & & $\begin{array}{l}\text { Q6 While using VISIR, I was motivated to } \\
\text { continue carrying out the experiment }\end{array}$ \\
\hline & & I don't have problems with the assigned time \\
\hline & & $\begin{array}{l}\text { Q8 } \begin{array}{l}\text { Moving between the breadboard page and } \\
\text { other equipment and instrumentations pages } \\
\text { does not hinder my attention }\end{array}\end{array}$ \\
\hline & & $\begin{array}{ll}\text { Q9 As it is case with VISIR, placing the } \\
\text { breadboard on a separate page and the other } \\
\text { equipment on another simplified my } \\
\text { interaction with system }\end{array}$ \\
\hline & \multirow{4}{*}{ 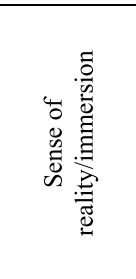 } & Q10 I felt that VISIR is real and not virtual \\
\hline & & $\begin{array}{l}\text { Q11 The equipment and instrumentations in } \\
\text { VISIR are identical to their real equivalence. }\end{array}$ \\
\hline & & $\begin{array}{l}\text { Q12 Although I am far from the VISIR, I have felt } \\
\text { myself to be in control of it }\end{array}$ \\
\hline & & $\begin{array}{l}\text { Q13 I would like to have a webcam (clock, a } \\
\text { device, a screen, etc.) at the side of the lab } \\
\text { server, in order to improve my interaction } \\
\text { between the users and the remote lab }\end{array}$ \\
\hline & \multirow{4}{*}{ 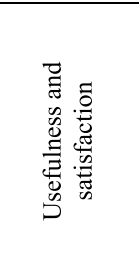 } & $\begin{array}{l}\text { Q14 I think using VISIR will strengthen both my } \\
\text { skills and theoretical background }\end{array}$ \\
\hline & & Q15 I would like to use VISIR in other subjects. \\
\hline & & $\begin{array}{l}\text { Q16 I think that remote labs such as VISIR serve } \\
\text { as a complement to hands-on }\end{array}$ \\
\hline & & $\begin{array}{l}\text { Q17 I think if two or more students located at } \\
\text { different places have the opportunity to work } \\
\text { together on an experiment, this will stimulate } \\
\text { the collaborative working between students }\end{array}$ \\
\hline
\end{tabular}

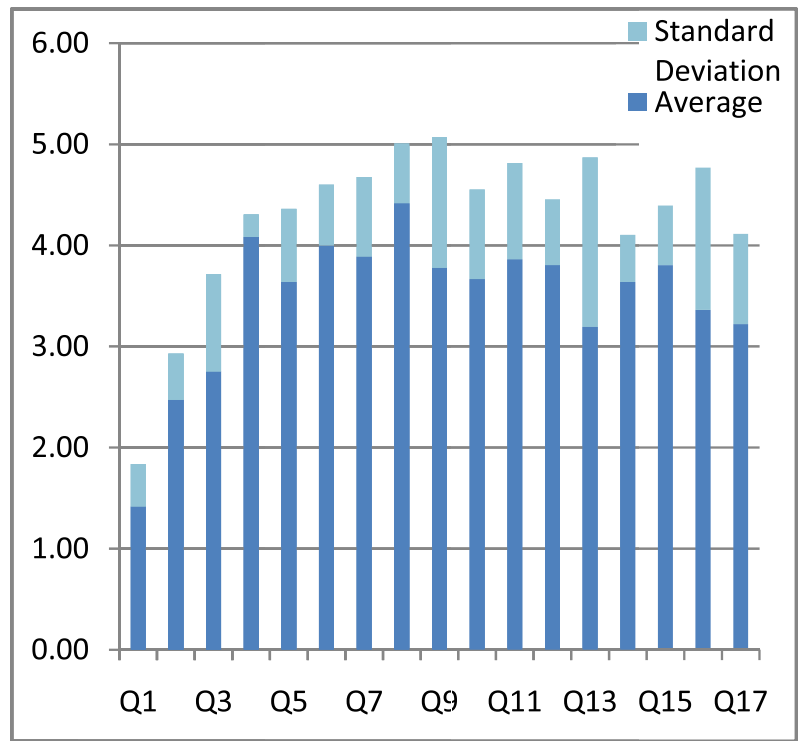

Fig. 5. Survey results of the survey questions.

and leads to the fact that an increased number of students must work on the same experiment.

Most of the survey questions about VISIR have a high mean compared to the ones concerned with the traditional labs. 


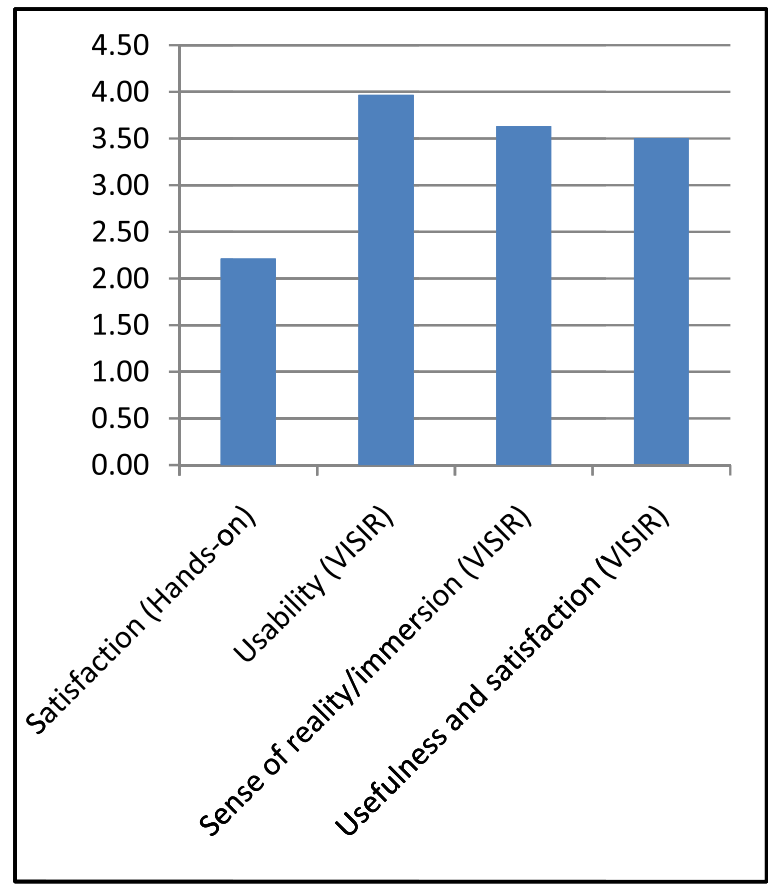

Fig. 6. Evaluation results of the evaluation criteria.

As it can be seen from Table II, three survey questions, namely, Q4: "Using VISIR is easy and convenient", Q6: "While using VISIR, I was motivated to continue carrying out the experiment", and Q8: "Moving between the breadboard page and other equipment and instrumentations pages does not hinder my attention" have values greater than 4, reflecting that the user-interface is user-oriented and adapted to the students' needs in the engineering and scientific lab. Another interesting result to be highlighted is the preference of having the breadboard on a separate page and the other components on another which obtained a value close to four. Distributing the virtual components on several pages is the preferred version for the students and a plausible interpretation for this is that students do not prefer to have many different presentations and information on one page because it is confusing for them. The survey question Q5 exposes that during an experiment session, there was no necessity for the instructor's help, which means that the system design and its functional structure are designed in such a way that the user will be supported in a correct manner through VISIR. In all, the criterion "Usability" obtained a relatively high value compared with other criterion as depicted in Fig. 6, in which the results of the various evaluation criteria "satisfaction of hands-on", "usefulness and satisfaction", "sense of reality/immersion" and "usability" are compared graphically.

It is clear that the survey question Q13 about adding some modifications such as a Webcam has a relatively high variance value, which shows that the students have different opinions. As an example, one of the students argued that it is necessary to have access to real devices, for example, through a live webcam because they would feel like they were doing real experiments and led to a deeper engagement with the task. Callaghan et al. [29] point out that this is of great

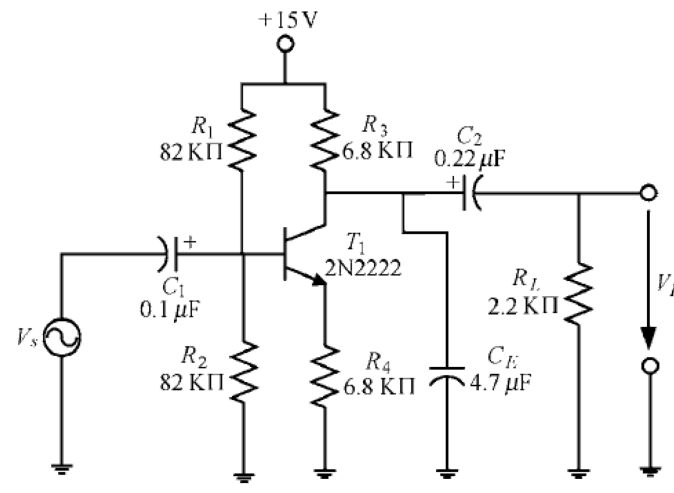

Fig. 7. A common emitter amplifier circuit.

significance as it would allow the students to move seamlessly from virtual representations of test equipment in a remote lab environment to actual test equipment in a real lab and to be capable of using this equipment competently as a direct result of their online experiences. The criterion "Usefulness and satisfaction" achieved a relatively high value, this meaning that the students find VISIR useful and satisfy their experimentation needs. The students would also like to extend VISIR into a collaborative working environment. A collaborative lab is an open lab spanning multiple geographical areas where collaborators interact via electronic means for encouraging closer relationships between students in an implemented lab's experiment remotely [30].

3) Stage Two (A Comparative Assessment): In the second stage, which will be at the beginning of the next academic year 2014/2015, a comparative assessment with a group of more than 50 engineering students from the two departments, Electronics and Computer Engineering, will be carried out. A more complicated electronic circuit, particularly, a common emitter amplifier circuit for measuring either the lower or the upper cutoff frequencies is selected because of the fact that, in this stage, the goal of this assessment is to find out strengths and weaknesses of remote labs represented here by VISIR in comparison with its traditional and simulation equivalences. That is, a categorization of VISIR in the laboratory landscape will give us an imagination of its location in this space. While Fig. 7 shows the circuit of the common emitter amplifier to be used in the planned evaluation, Fig. 8 presents its experimental realization on the virtual breadboard of VISIR.

In the comparative evaluation, the remote lab approaches serve as independent variables, whereas the evaluation criteria serve as dependent variables. It will be possible to measure the differences between the different types of labs according to what extent the fundamental course objectives of engineering instructional labs [31], [32]: student's retention rate and satisfaction survey, as well as their performance are fulfilled. The statistical outcome should be analyzed and reviewed by the system designers and developers in such a way that the results will help in revising and optimizing the design of the interactive software system on the one hand; on the other hand, the system designers could have defined new or corrected existing design guidelines for future remote labs. As a useful means for comparing mean values of two sets of numbers, 


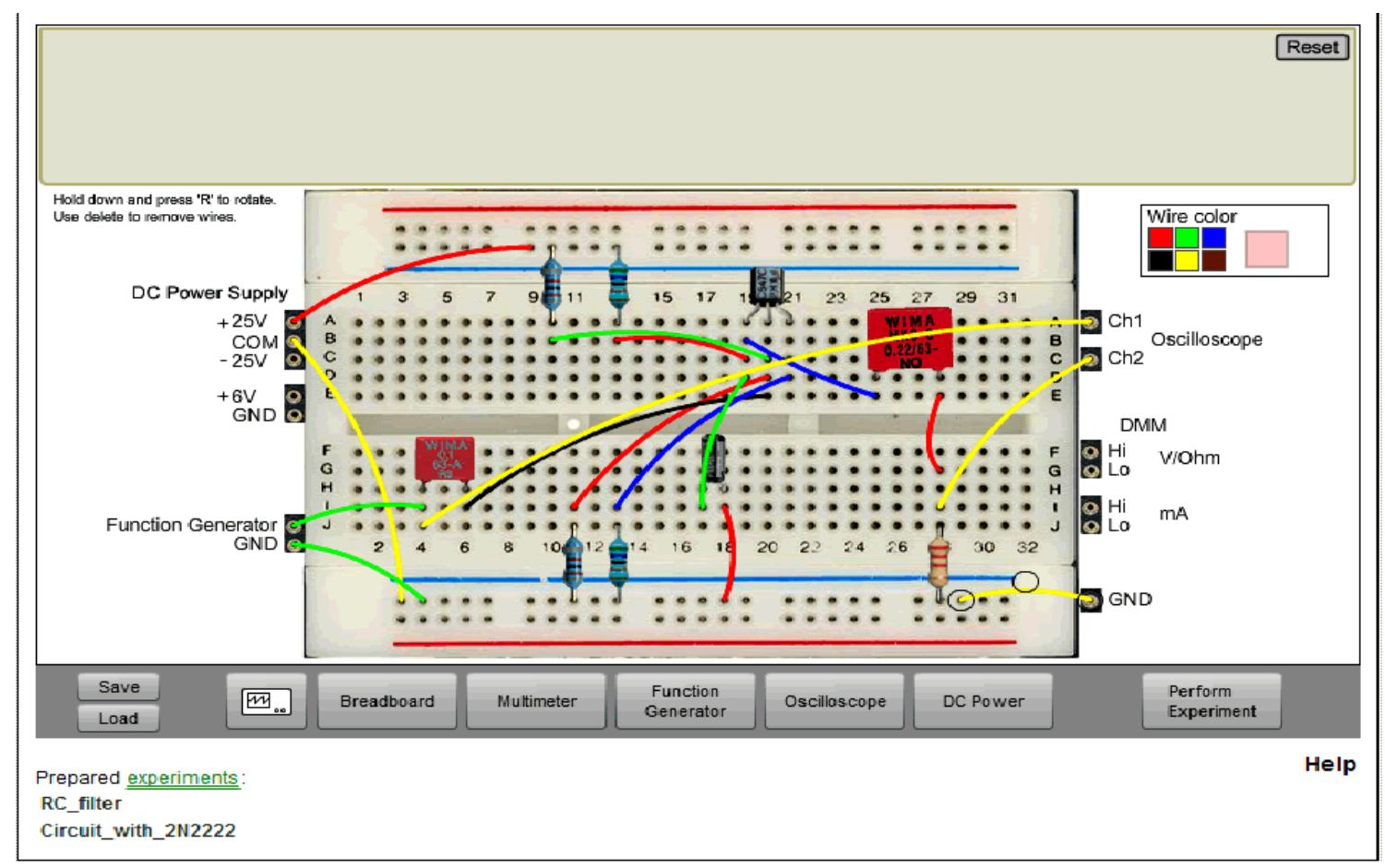

Fig. 8. A virtual presenataion of the common emmitter amplifier circuit on the virtual breadboard of VISIR.

system evaluators have the opportunity to select between either the Student's test (t-test) or one-way ANOVA [7], through which a comparison can be carried out, providing us with a statistic for evaluation exposing the statistical significance of the difference between two means. During a usability testing session, the experiment coordinator explains to the students all operations related to the experiment, VISIR and the simulated experiment, for example using PSpice, which is a software program for simulating analog and digital circuits.

In a comparative evaluation, a dependent variable is a factor determined by another variable called the independent variable. In other words, the independent variable causes an apparent change in, or simply affects, the dependent variable. In analysis, researchers usually want to explain why the dependent variable has a given value. As mentioned, the values of a dependent variable in different settings are usually compared; whereas an independent variable is presumed to affect or determine a dependent variable. Usability engineers or system evaluators control/change the independent variable, which causes the dependent variable to change as a result since independent variables act as catalysts for dependent variables. That is, the independent variable is the "presumed cause" while dependent variable is the "presumed effect" of the independent variable [33].

For comparing the different labs correctly, it is of great importance to define the appropriate assessment criteria, through which differences between the three labs approaches: traditional, remote and simulated labs can be extracted. For a successful assessment of laboratory course objectives, we will focus on three major components. These are student's retention rate and satisfaction survey, as well as their performance. These assessment criteria will be measured for three practical sessions with different students, instructors

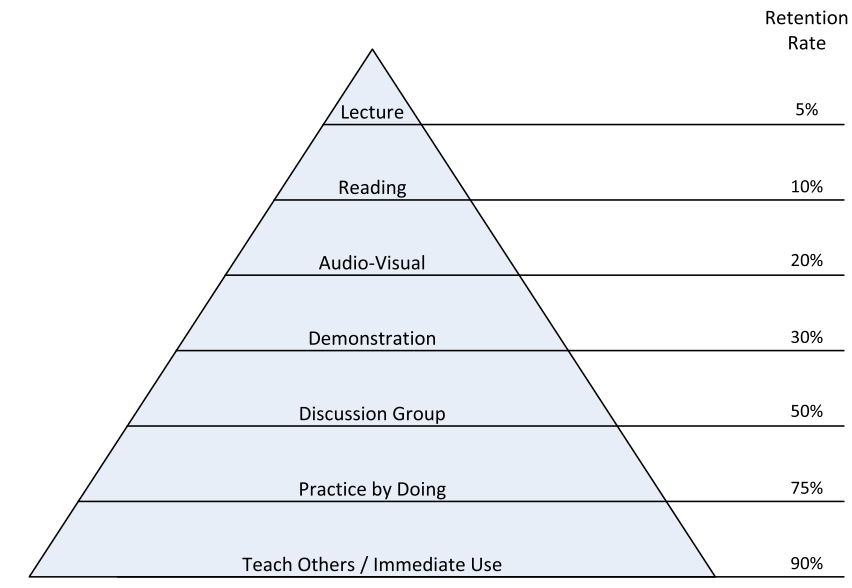

Fig. 9. Teaching methods and retention rates [34].

and technicians conducting the same experiment using the hands-on, simulation and the remote VISIR approaches. Furthermore, another group will be asked to perform the same experiment using the three methods. Accordingly, a comparative study will be performed to compare the retention rate, students' performance and their satisfactions. The three assessment methodologies are:

- Retention Rate: In engineering labs, students are essentially expected to work in groups, "practice by doing" and "teach others". We should recall that the various methods of teaching include Lecture, Reading, Audio-Visual, Demonstration, Discussion Group, Practice by Doing, and Teach Others/Immediate Use. The retention rates that correspond to each teaching have been demonstrated by Singhal et al. [34] and depicted in Fig. 9. It is clear from the figure that the "Lecture" as a teaching method is the least effective one from the retention 
viewpoint. The "Practice by Doing" teaching method has a $75 \%$ retention rate; whereas, "Teach Others/Immediate use" has a $90 \%$ retention rate. We believe as instructors that the "Practice by Doing" component will be completed by the build-and-test phase of the teaching process, otherwise, the teaching method and the educational impact will be less effective. Furthermore, by allowing the students to work in groups, we enable students to experience the work in teams and practice the "Teach Others" element that has the highest retention rate.

- Satisfaction Survey: A survey-like questionnaire will be developed to measure the students', instructors' and technicians' satisfactions for the three models of covering the experiment.

- Student's Performance: For the student's performance, we have to assess the thirteen fundamental objectives of engineering instructional laboratories [32]. These essential objectives should be provided and accordingly used as a measure to assess the students' competencies and performance with respect to the experiment they will conduct. These objectives can be categorized into three types. The first type that deals with cognitive aspects such as Instrumentation, Models, Experiment, Data Analysis and Design. The second category involves the psychomotor that targets the ability to actually manipulate apparatus and the Sensory Awareness, Learn from Failure, Creativity, Psychomotor, Safety, Communication, Teamwork, Ethics in the Laboratory and Sensory Awareness. The last two-fold category includes cognitive and emotional behaviour and attitudes fields. These objectives include learn from failure, creativity, safety, communication, teamwork, and ethics in the laboratory.

\section{COnClusions}

Simulators are tools that students, especially in engineering, use to learn theories taught in courses. However, physical experiments are indispensable to explore strengths and limitations of these theories as models of phenomena of nature and to get an accurate understanding of what is happening in real life. A metaphor of experimenting is an interview with nature. The experimentalist asks a question, for example, what is the sum of the currents into a tie point of an electric circuit and nature answers. The delicate task is formulating useful questions but above all it is interpreting the answers. Students must perform many experiments and must become familiar with the equipment in the lab in order to be fluent in the "language of nature". ABET has formulated fundamental learning objectives of engineering instructional labs including both limitations of theories and appropriate experimental approaches as well as data interpretation. However, the hands-on lab sessions offered at most universities are too few to allow the students to achieve the objectives.

Today it is possible to open labs for remote access 24 hours a day/7 days a week using a web browser only. VISIR remote labs for electrical experiments that support the ABET objectives supplement university hands-on labs where students perform experiments using breadboards. For more than five years, many students at several universities globally are using such VISIR labs located at a number of universities in Europe. The experiences of applying VISIR in the Engineering Faculty at Al-Quds University in Jerusalem in Palestine include a survey where 71 engineering students have answered a questionnaire comprising 17 closed-ended questions. The first stage of the evaluation accomplished by a survey instrument was concerned with measuring the students' acceptance, satisfaction etc. of introducing such technology at the engineering faculty; it shows that the students find VISIR useful and it satisfies their experimentation needs. In the second stage of our evaluation study, a more in-depth comparative analysis will be done at the beginning of the next academic year 2014/2015 in order to have a classification of VISIR in the landscape of other kinds of engineering laboratories such as traditional hands-on and simulations, for example, PSpice. This classification is in accordance with the fundamental course objectives of engineering instructional labs: student's retention rate and satisfaction survey, as well as their performance.

\section{ACKNOWLEDGMENTS}

Many thanks go to the VISIR group at ISEP in Porto in Portugal for their acceptance for accessing and testing VISIR using their VISIR lab as well as for the preparation of the remote experiment. This study would not have been possible without their acceptance and allowance to access the remote lab.

This paper presents an extended version of a paper entitled as "Experiences with Deploying VISIR at Al-Quds University in Jerusalem", which was presented at IEEE EDUCON 2014: 2014 IEEE Global Engineering Education Conference (EDUCON), 3-5 April, Istanbul, Turkey [35].

\section{REFERENCES}

[1] ABET. Criteria for Accrediting Engineering Programs [Online]. Available: http://www.abet.org/accreditation/accreditation-criteria/criteria-foraccrediting-engineering-programs-2015-2016/, accessed Feb. 2, 2015.

[2] S. Dormido et al., "Using Web-based laboratories for control engineering education," in Proc. Int. Conf. Eng. Edu., Coimbra, Portugal, Sep. 2007, pp. 1-6.

[3] Z. Nedic, J. Machotka, and A. Nafalski, "Remote laboratories versus virtual and real laboratories," in Proc. 33rd ASEE/IEEE Frontiers Edu. Conf., Boulder, CO, USA, Nov. 2003, pp. T3E-1-T3E-6.

[4] W. J. Hutzel, "A remotely accessed HVAC laboratory for distance education," Int. J. Eng. Edu., vol. 18, no. 6, pp. 711-716, 2002.

[5] S. Odeh, "Building reusable remote labs with adaptable client userinterfaces," J. Comput. Sci. Technol., vol. 25, no. 5, pp. 999-1015, 2010.

[6] M. Tawfik et al., "Virtual instrument systems in reality (VISIR) for remote wiring and measurement of electronic circuits on breadboard," IEEE Trans. Learn. Technol., vol. 1, no. 6, pp. 60-72, Jan./Mar. 2013.

[7] R. A. Johnson and G. K. Bhattacharyya, Statistics: Principles and Methods. New York, NY, USA: Wiley, 2000.

[8] J. Pallant, SPSS Survival Manual. Maidenhead, U.K.: Open Univ. Press, 2004.

[9] J. Ma and J. V. Nickerson, "Hands-on, simulated, and remote laboratories: A comparative literature review," ACM Comput. Surv., vol. 38, no. 3, 2006, Art. ID 7.

[10] E. C. Valentin, A. Verbraeck, and H. G. Sol, "Advantages and disadvantages of building blocks in simulation studies: A laboratory experiment with simulation experts," in Proc. 15th Eur. Simulation Symp., 2003, pp. 141-148.

[11] B. Guimaraes, A. S. Souza, H. L. Gosmann, and A. Bauchspiess, "Internet based remote laboratory: The level control of three coupled water reservoirs," in Proc. ACCA, Santiago, Chile, 2002, pp. 1-6. [Online]. Available: http://www.ene.unb.br/adolfo/Papers/acca2002.pdf 
[12] I. Gustavsson et al., "On objectives of instructional laboratories, individual assessment, and use of collaborative remote laboratories," IEEE Trans. Learn. Technol., vol. 2, no. 4, pp. 263-274, Oct./Dec. 2009.

[13] Z. Nedic, J. Machotka, A. Sprok, L. O. Ruud, and S. Carr, "The circuit builder for NetLab," in Proc. 8th UICEE Annu. Conf. Eng. Edu., Kingston, Jamaica, Feb. 2005, pp. 239-242.

[14] I. Gustavsson, T. Olsson, H. Åkesson, J. Zackrisson, and L. Håkansson, "A remote electronics laboratory for physical experiments using virtual breadboards," in Proc. ASEE Annu. Conf. Expo., Portland, OR, USA, Jun. 2005, p. 13.

[15] I. Gustavsson, J. Gustavsson, and T. Olsson, "Traditional lab sessions in a remote laboratory for circuit analysis," in Proc. 15th EAEEIE Annu. Conf. Innov. Edu. Elect. Inf. Eng., Sofia, Bulgaria, May 2004, pp. 1-6.

[16] J. García-Zubía, I. Gustavsson, U. Hernández-Jayo, P. Orduña, I. Angulo, and J. Ruiz-de-Garibay, "El proyecto VISIR en la universidad de Deusto: Laboratorio remoto para electrónica básica," in Proc. 9th Congreso Tecnologí Aplicadas Enseñanza Electrón. (TAEE), Madrid, Spain, Apr. 2010, p. 13.

[17] M. Tawfik et al., "VISIR: Experiences and challenges," Int. J. Online Eng., vol. 8, no. 1, pp. 25-32, 2012.

[18] B. Shneiderman, C. Plaisant, M. Cohen, and S. Jacobs, Designing the User Interface: Strategies for Effective Human-Computer Interaction, 5th ed. Reading, MA, USA: Addison-Wesley, 2010.

[19] J. P. Chin, V. A. Diehl, and K. L. Norman, "Development of an instrument measuring user satisfaction of the human-computer interface," in Proc. SIGCHI Conf. Human Factors Comput. Syst., 1988, pp. 213-218.

[20] SUMI: Software Usability Measurement Inventory. [Online]. Available: http://sumi.ucc.ie/whatis.html, accessed Feb. 10, 2015.

[21] MUMMS: Measuring the Usability of Multi-Media Software. [Online]. Available: http://www.ucc.ie/hfrg/questionnaires/mumms/index.html

[22] CSUQ: Computer System Usability Questionnaire. [Online]. Available: http://hcibib.org/perlman/question.cgi, accessed Feb. 10, 2015.

[23] A. A. Ozok, "Survey design and implementation in HCI," in Human Computer Interaction Handbook: Fundamentals, Evolving Technologies, and Emerging Applications, 2nd ed. A. Sears and J. Jacko, Eds. New York, NY, USA: Taylor \& Francis, 2008, pp. 1151-1169.

[24] U. Reja, K. L. Manfreda, V. Hlebec, and V. Vehovar, "Open-ended vs. close-ended questions in Web questionnaires," in Inevelopments in Applied Statistics, A. Ferligoj and A. Mrvar, Eds. Ljubljana, Slovenia: Metodoloski Zvezki, 2003, pp. 159-177.

[25] M. B. Rosson and J. M. Carroll, Usability Engineering: Scenario-Based Development of Human-Computer Interaction. San Diego, CA, USA: Academic, 2002, pp. 15-22.

[26] M. B. Rosson, S. Maass, and W. Kellogg, "The designer as user: Building requirements for design tools from design practice," Commun. ACM, vol. 31, no. 11, pp. 1288-1298, 1989.

[27] K. Weidenhaupt, K. Pohl, M. Jarke, and P. Haumer, "Scenarios in system development: Current practice," IEEE Software, vol. 15, no. 2, pp. 34-45, Mar./Apr. 1998.

[28] P. Milgram and F. Kishino, "A taxonomy of mixed reality visual displays," IEICE Trans. Inf. Syst., vol. E77-D, no. 12, pp. 1321-1329, 1994.

[29] M. J. Callaghan, J. Harkin, T. M. McGinnity, and L. P. Maguire, "Client-server architecture for remote experimentation for embedded systems," Int. J. Online Eng., vol. 2, no. 4, pp. 1-6, 2006

[30] S. Odeh and E. Ketaneh, "E-collaborative remote engineering labs," in Proc. IEEE Global Eng. Edu. Conf. (EDUCON), Marrakesh, Morocco, Apr. 2012, pp. 1-10.

[31] L. D. Feisel and A. J. Rosa, "The role of the laboratory in undergraduate engineering education," J. Eng. Edu., vol. 94, no. 1, pp. 121-130, Jan. 2005.

[32] L. D. Feisel and G. D. Peterson, "A colloquy on learning objectives for engineering education laboratories," in Proc. ASEE Annu. Conf. Expo., Montreal, QC, Canada, Jun. 2002, pp. 1-12.

[33] N. A. Streitz, "Cognitive compatibility as a central issue in humancomputer interaction: Theoretical framework and empirical findings," in Cognitive Engineering in the Design of Human-Computer Interaction and Expert Systems, G. Salvendy, Ed. Amsterdam, The Netherlands: Elsevier, 1987, pp. 75-82.

[34] A. C. Singhal, L. Bellamy, and B. McNeill, "A new approach to engineering education," Arizona State Univ., Tempe, AZ, USA, Tech. Rep., 1997, p. 88.

[35] S. Odeh, G. R. Alves, M. Anabtawi, M. Jazi, M. Arekat, and I. Gustavsson, "Experiences with deploying VISIR at Al-Quds University in Jerusalem," in Proc. IEEE Global Eng. Edu. Conf. (EDUCON), Istanbul, Turkey, Apr. 2014, pp. 273-279. [Online]. Available: http://dx.doi.org/10.1109/EDUCON.2014.6826102

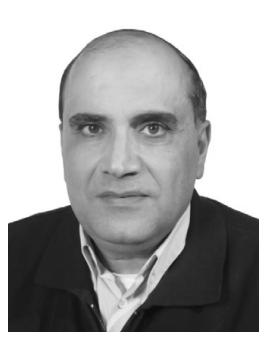

Salaheddin Odeh received the master's degree in electrical engineering from the University of Stuttgart, Germany, in 1992, and the Ph.D. degree from the University of Kassel, Germany, in 1998. From 1992 to 1998, he was a Staff Member with the Institute of Human-Machine Systems Engineering, University of Kassel, where he was involved in research projects about participative and multimodal design of human-machine interfaces in process control funded by the German Research Foundation. From 1998 to 2001, he acted as an IT Consultant with Sun Microsystems, where he was involved in the operating system Solaris in two industrial projects of the German Post Deutsche Post AG and the Irish Bank first e-solutions in Darmstadt and Frankfurt, Germany. From 2004 to 2007, he acted as the Chair of the Department of Computer Engineering and a Coordinator of the master's program with the Faculty of Engineering. Since 2002, he has been an Associate Professor of Electrical and Computer Engineering with the Faculty of Engineering, Al-Quds University. $\mathrm{He}$ is currently the Head of the Computer Engineering Department with the Faculty of Engineering, and the Foundation Director of the Dual Study Electrical Engineering Programs with cooperation of the German Government. His research interests include educational remote labs, software engineering, control engineering, advanced programming, distributed systems and cloud computing, human-computer interaction, and image processing. He is a member of the Board of Directors of the Supreme Council for the Adoption and Rehabilitation of Engineers-The Palestinian Engineers Association, a member of the Scientific Committee for Engineering and Science-the Ministry of Higher Education in Palestine, and a member of the Board of Directors of the Palestinian Scientific Society for Innovation and Development. He was a recipient of the Best Doctoral Thesis Award from the Association of German Engineers for his Ph.D. thesis titled Approximate KnowledgeBased Process Visualization on the Basis of Fuzzy Logic in 1999. He was also a recipient of the IEEE Best Paper Award for his research paper E-Collaborative Remote Engineering Labs at the IEEE Global Engineering Education in Marrakesh, Morocco, in 2012.

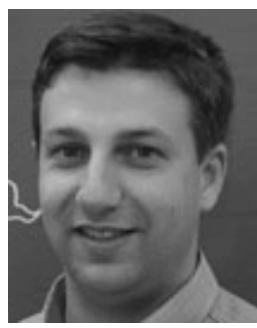

Joaquim Alves received the degree, the M.Sc. degree in electrical and computer engineering, and the Ph.D. degree in engineering sciences from the University of Porto, Portugal, in 1994, 1998, and 2007, respectively. He oriented several degrees and master's projects/internships in the fields of instrumentation, automation, metrology, and biologic signal processing. Since 1997, he has been an Adjunct Professor with the Department of Physics, School of Engineering, Polytechnic of Porto. Since 2005, he has been responsible for the data acquisition and data management and biological signal processing curricular units in the Computing Engineering and Medical Instrumentation degree and the Instrumentation Engineering and Metrology degree, and also responsible for the curricular units of applied metrology of the Instrumentation Engineering and Metrology Master degree since 2013. He has been the Head of the Instrumentation Engineering and Metrology Master since 2012. $\mathrm{He}$ has a strong background in the fields of optoelectronics instrumentation and civil engineering structures monitoring. He has participated as an Investigator in research projects and has authored several papers in journals and international conferences with peer-review. Since 2012, he has been an Investigator with the LABORIS Research Group, part of the Center for Innovation in Engineering and Industrial Technology. 


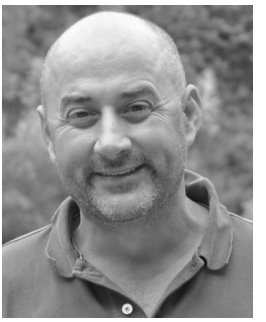

Gustavo Riberiro Alves (M'14) received the M.Sc. and Ph.D. degrees in electrical and computer engineering from the University of Porto, Portugal, in 1995 and 1999, respectively. He has been an Adjunct Professor with the Department of Electrical Engineering, School of Engineering, Polytechnic of Porto, since 1994. He is responsible for the Research Group in Systems Testing, part of the Center for Innovation in Engineering and Industrial Technology. He has authored over 145 articles in journals and international conferences with peer-review. He co-edited a book in the area of remote labs in 2011. His areas of interest include teaching in engineering, remote experimentation, and electronic systems debug and test. $\mathrm{He}$ is a member of the Global Online Laboratory Consortium, the International Society for Engineering Education, the Portuguese Society for Engineering Education, and the Order of Engineers in Portugal.

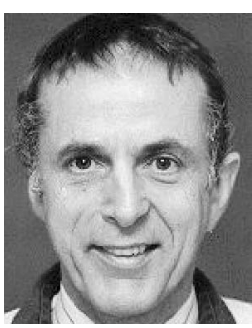

Ingvar Gustavsson received the M.S.E.E. and Dr.Sc. degrees in electrical engineering from the Royal Institute of Technology (KTH), Stockholm, in 1967 and 1974, respectively. After completing his military service in 1968, he worked as a Development Engineer at Jungner Instrument $\mathrm{AB}$ in Stockholm. In 1970, he joined the computer vision project SYDAT at the Instrumentation Laboratory, KTH. In 1982, he was appointed the head of the Instrumentation Laboratory. Together with another research scientist, he founded a private company providing automatic inspection systems for industrial customers in 1983. In 1994, he returned to the academic world to take up his current position as an Associate Professor of electronics and measurement technology at Blekinge Institute of Technology (BTH), Sweden. In 1999, he started a remote lab project at BTH that today is known as VISIR (Virtual Instrument Systems in Reality). The GOLC Online Laboratory Award in the category "Remote Controlled Lab" was presented to VISIR in 2015. Dr. Gustavsson partly retired from office 2012 making it possible to concentrate on activities related to VISIR. He is still a member of Swedish professional societies and of the IEEE. His research interests are in the areas of instrumentation, remote labs, industrial electronics, and distance learning.

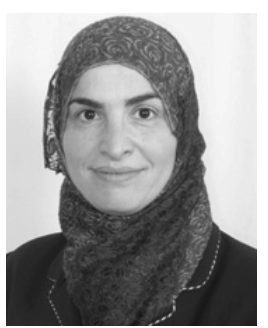

Mahasen Anabtawi joined the Computer Engineering Department, Al-Quds University, in 1999, as an Assistant Professor. She was the Chair of the Computer Engineering Department for two years (2005-2007). She supervised different undergraduate projects. She acted as an Internal and External Examiner to a number of master's theses. She was a Coordinator of the master's program with the Engineering Faculty. She was the Dean of the Faculty of Engineering with Al-Quds University from 2009 to 2012. She has authored several research articles in different journals and conferences. She has served as a member of several committees at the university.

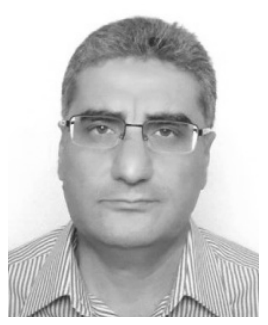

Labib Arafeh is an Associate Professor of Computing and the Dean of the Faculty of Engineering with Al-Quds University. His research interests lie in the major aspects of computing applications for people and lifelong learning; project management knowledge areas' modeling and auto essay grading systems; the development of models of quality e-learning systems (from different dimensions, such as contents and multimedia, interface, usability, production, tools, and institutional and technical support); the development of e-learning systems for theoretical and practical (experimental) courses to promote lifelong learning for users of different ages and genders; quality assurance and evaluation of e-learning systems, Web sites, and portals; using one of the latest management and development tools, including Agile approach to enhance efficiency, productivity, cost effectiveness, and proficient management; and promoting the use of technology in teaching, and the production of educational and cultural multimedia, including the augmented reality.

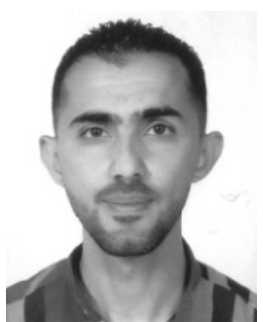

Mahran Jazi received the bachelor's degree in electronics engineering and the M.Sc. degree in electronic and computer engineering from Al-Quds University, Palestine, in 2011 and 2015, respectively. He joined Palestine CD project in Germany to work on his thesis, which titled Development of a Software Defined Radio Testbed for RFID Generation-2 Reader. His current research areas include medium access control protocols for wireless networks, RFID anticollision protocols, cognitive radio, and digital signal processing specialized in speech recognition.

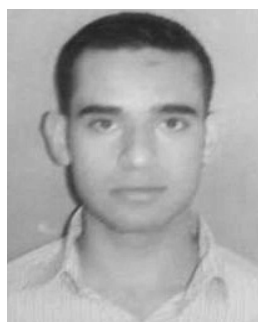

Mahmoud R. Arekat received the bachelor's degree in computer engineering from Al-Quds University, in 2013. He is currently pursuing the master's degree in business administration. He is a Computer Engineer, and a Database Administrator with $\mathrm{Al}$ Quds University. He recently launched a new startup developing video games for specific purposes, such as learning and marketing. His research interests lie in using interactive methods for learning and assessment, such as e-learning, distance learning systems, and educational video games. 